\title{
Percutaneous nephrolithotomy-a versatile technique for both simple and complex renal stone
}

\author{
Hossain $\mathrm{TMS}^{1}$, Asaduzzaman $\mathrm{M}^{2}$, Uddin $\mathrm{MN}^{2}$, Rahman $\mathrm{MH}^{2}$, Jahan $\mathrm{MU}^{3}$, Bhuiyan $\mathrm{AKMZI}^{2}$ \\ ${ }^{1}$ Department of Urology, Bangabandhu Sheikh Mujib Medical University, Dhaka, \\ ${ }^{2}$ Department of Urology, National Institute of Kidney Diseases \& Urology, Dhaka, \\ ${ }^{3}$ Department of Radiology and Imaging, Bangabandhu Sheikh Mujib Medical University, Dhaka. \\ Email:dr.tmsh@yahoo.com
}

\begin{abstract}
Percutaneous Nephrolithotomy is currently the preferred first line treatment for simple \& complex renal calculi. The technique also being used increasingly for smaller stones that have failed ESWL. Aim of the study is to share our experience in PCNL in course of time. This study was conducted from January 2009 to December 2012, 131 patient's with142 renal units of 5-75 yrs of age, PCNL were performed in NIKDU, BSMMU \& JBFH. Stone were classified into simple (isolated renal pelvis or isolated calyceal stones) or complex (partial or complete staghorn stones, renal pelvic stone with accompanying calyceal stones). The stone size was $1.5-5 \mathrm{~cm}$ approximately. We asses our initial puncture technique, need for multi-tract, supra $12^{\text {th }}$ rib access, stone free rate, operative duration, postoperative complication, number of transfusion and hospital stay. Operative durations were 60 min -180 minutes. Puncture technique improved in course of time. 14 patients need multi-puncture and tract, all are supra $12^{\text {th }}$ access. Out of 142 renal units $120(83 \%)$ were stone free after first procedure, another 22 need and auxiliary procedure, (5 2nd look PCNL, 6 URS, 11 ESWL) to become stone free result in a $95 \%$ stone free rate. Complications occurred in 17 procedures which dealt accordingly. This study revealed PCNL is an effective, versatile safe and cosmetically acceptable procedure for all age groups in simple and complex renal stone.
\end{abstract}

\section{Introduction}

The advent and continuous evolution of percutaneous nephrolithotomy (PCNL) have led to a revolution in the management of renal stones ${ }^{\mathbf{1 , 2}}$. PCNL is now the preferred treatment for patients with renal calculi and is a safe and successful method used for removal of different types of stones $^{3}$. The technique is also being used increasingly for smaller stones that have failed Extra Corporeal Shockwave lithotripsy (ESWL) or where in the anatomy of the collecting system would likely result in a lesser chance of success with ESWL. The morbidity of PCNL is less than that open surgery with better stone-clearance rates ${ }^{\mathbf{4 , 5}}$. With increasing stone size and complexity, PCNL may require a longer operative time, larger volumes of irrigant fluid, and multiple tracts to achieve complete stone clearance ${ }^{6}$.

The traditional subcostal access is preferred in percutaneous renal surgery to avoid injury to the lungs and pleura ${ }^{7}$. However, in some patients, such as those with upper calyceal stones, impacted upper ureteral stones, staghorn calculi, and in obtaining access to the ureteropelvic junction (UPJ), the supracostal approach may be the most direct means to achieve a satisfactory result. The supracostal approach used to be avoided for fear of potential chest complications. However, knowledge of the pleural and diaphragmatic anatomy and refinement of the surgical technique have reduced these complications to a minimum.

Now a days, PCNL should be the first-line treatment for large or multiple kidney stones and stones in the inferior calyx. Furthermore, improvements in instruments (i.e., nephroscopes and ureteroscopes) as well as lithotripsy technology (i.e., ultrasound/pneumatic devices, holmium/ yttrium-aluminum-garnet laser) increased the efficacy of percutaneous stone disintegration yielding stone-free rates of $>90 \%{ }^{\mathbf{8 , 9}}$.

PCNL is generally a safe treatment option and associated with a low but specific complication rate $^{\mathbf{1 0}}$. Many complications develop from the initial puncture with injury of surrounding organs (e.g., colon, spleen, liver, pleura, and lung). Other specific complications include postoperative bleeding and fever.

Based on personal experience and an overview of the literature, we present PCNL as a step-by-step 
approach including the stone clearance, the description of possible complications and their origin and management adequately.

\section{Materials and Methods}

From January 2009 to December 2012, 131 patients with142 renal units of 5-75 years of age, male 75 and female 67 (Table-I). PCNL was performed in National Institute of Kidney Diseases \& Urology (NIKDU), Bangobandhu Sheikh Mujib Medical University (BSMMU) \& Japan Bangladesh Friendship Hospital (JBFH). Patient demographics, stone, and operative information were documented prospectively. Postoperative information, including length of hospital stay, complications, auxiliary treatments, postoperative drop in hemoglobin level, and need for transfusions were recorded.

Stone were classified into simple (isolated renal pelvis or isolated calyceal stones) (Fig. 1A) or complex (partial or complete staghorn stones, renal pelvic stone with accompanying calyceal stones) (Fig. 1B, 1C). The stone size was $1.5-5 \mathrm{~cm}$ approximately. Simple stone 109, Complex stone 33 and $\mathrm{B} / \mathrm{L}$ stone 11 .

Procedural technique.

All PCNL procedures were performed in a teaching environment using the same technique under general anesthesia and a few cases under Sub Arachnoid Block (SAB). At first, patient placed in lithotomy position and retrograde access was obtained with ureteric catheter over guide wire. Then ureteral catheter was secured to a Foley catheter. The patient was repositioned prone with adequate padding under the pressure points of the head, chest, knees, and feet. Percutaneous access was obtained at the time of surgery by the operating urologist in all 142 cases, without assistance from interventional radiology guidance. Based on the stone location, size, burden, and pelvicalyceal anatomy, the site of calyceal entry and number of access tracts were chosen at the procedure's commencement.

The architecture of the collecting system was delineated by contrast infused through the ureteral catheter with the patient supine. Two images are captured: One in the anterior-posterior plane and another in 30-degree lateral images. A bull's-eye technique was used to gain access directly into the center of the papilla of the chosen calyx, once the patient was placed in the prone-flexed position. Once intrarenal access is obtained, the tract is sequentially dilated from $6 \mathrm{~F}$ to $30 \mathrm{~F}$, and a safety guide wire is inserted (Fig.-2A).
The tract was dilated to 30Fr under fluoroscopic guidance, and access into the collecting system is confirmed by rigid nephroscopy. Once access was gained, pneumatic and ultrasonic lithotripter was used to fragment the stone. Tri-radiate forceps (Storz) are used to render the patient stone free. All 14 patients with supracostal access underwent fluoroscopy of the chest to exclude hydrothorax. Standrad PCNL (for adult) \& mini - PCNL (for children) done. For adult tract size 28-30 Fr \& $16 / 24$ Fr tract for children. 5Fr/6Fr JJ stent placed in situ after procedure, every calyx was checked at the end of the procedure, residual stones were either within papillae or small and inaccessible via the available tract or tracts, where it was considered unreasonable to insert an additional tract. 14/20/26FR Nephrostomy tube kept in situ after procedure (Fig. 2B). Postoperatively, the nephrostomy tube was removed after 24 hour.

We asses our initial puncture technique, need for multitract, supra $12^{\text {th }}$ access, stone free rate, operative duration, postoperative complication, number of transfusion and hospital stay.

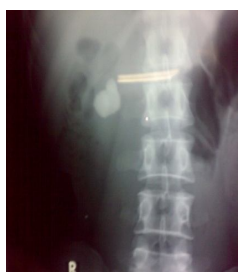

A

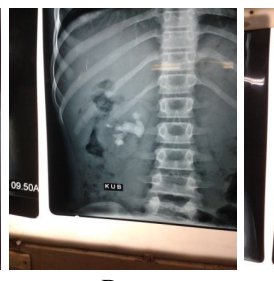

B.

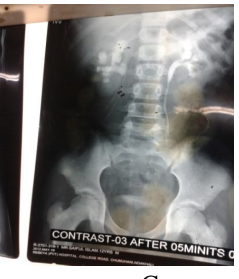

C
Fig. 1: A) Right renal stone. B) Right renal staghorn calculus. C) Right renal stone in IVU film.

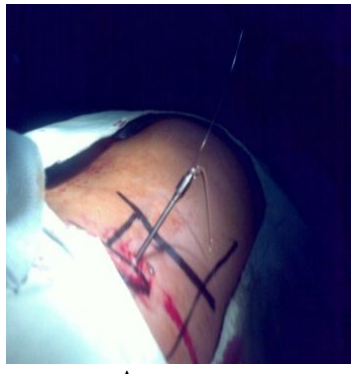

A.

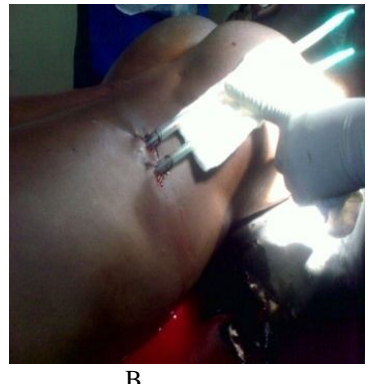

B.
Fig.-2: A) After Puncture. B) Double puncture.

\section{Results}

In our 142 renal units, the PCNL was on the right side in 85 and on the left side in 57. Renal access was obtained lower posterior calyceal puncture in 101, middle calyceal puncture 27 and above the twelfth rib in 14 (9 preplanned, 5 as $2^{\text {nd }}$ puncture) procedures (Fig.3). Operative time ranged between 60-180 minutes, with a mean of $90.83 \pm 29.13$ minutes. 


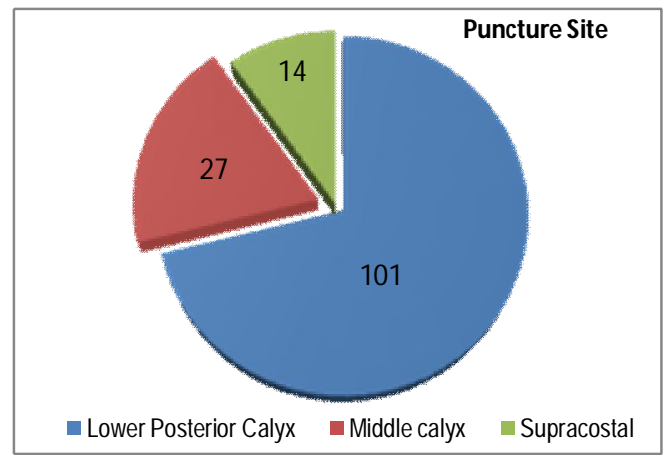

Fig.-3: Puncture Site

A renal unit was considered stone free when the postoperative radiograph of kidneys, ureters, and bladder (KUB) showed no or clinically insignificant stone fragments $(<2 \mathrm{~mm}) .116$ renal units were rendered free of stone material $(82 \%)$, as evidenced by intraoperative fluoroscopy and postoperative KUB radiography and/or ultrasonography after $1^{\text {st }}$ procedure. 22 needs auxiliary procedure like five patients need $2^{\text {nd }}$ look PCNL, six needs Ureoterorenoscopy (URS), \& eleven11 needs Extracorporeal Shock Wave Lithotripsy (ESWL) and ultimate stone free result in $93 \%$.

Four patients need conversion at our initial experience due to failed puncture. $128(90 \%)$ were completed with a single puncture and 14 procedures $(9.85 \%)$ were completed with two punctures, all of which were supracostal. Intraoperative bleeding occurred in four patients and haematuria occurs in 3 patients and clot retention in 1 patient. Total $8(5.63 \%)$ patients required blood transfusions. Perforation of calyceal system occurs in 6 patients and migration of stone fragments outside pelvi-clyceal system (PCS) occurs in 4 patients (Table-II).

Colonic injury occurs in 2 cases which were managed conservatively. No patient developed hydrothorax which was confirmed by fluroscopy intraoperatively and postoperatively by chest Xray. Fever developed postoperatively in eleven patients. The fever subsided with conservative management. The mean length of hospital stays 3.28 \pm 0.77 (range 3-7 days) days.

Table I: Patient's characteristics

\begin{tabular}{|c|c|c|}
\hline \multicolumn{2}{|c|}{ Age } & $5-75$ years \\
\hline \multicolumn{3}{|c|}{ Sex } \\
\hline & Male & 75 \\
\hline & Female & 67 \\
\hline Stor & & $1.5-5 \mathrm{~cm}$ \\
\hline \multicolumn{3}{|c|}{ Stone character } \\
\hline & Simple stone & 109 \\
\hline & Complex stone & 33 \\
\hline \multicolumn{3}{|c|}{ Side } \\
\hline & Right & 85 \\
\hline & Left & 57 \\
\hline
\end{tabular}

Table II: OUTCOME

\begin{tabular}{ll}
\hline Characteristics & Outcome \\
\hline Stone free & $93 \%$ \\
Postoperative fever (n) & 11 \\
Bleeding (n) & 08 \\
Perforation collecting system (n) & 06 \\
Colonic Injury (n) & 02 \\
Blood transfusion (n) & 08 \\
Failed puncture (n) & 04 \\
Mean \pm SD operative time (mins) & $90.83 \pm 29.13$ \\
Mean \pm SD length of hospital stay (days) & $3.28 \pm .77$ \\
\hline
\end{tabular}

\section{Discussion}

PCNL is established as the main modality for managing large renal calculi since Fernstrom and Johanson first used a nephrostomy tract to extract a stone in $1976^{11}$. PCNL is presently the most demanding operative technique. The difficulty is solely related to obtaining access to the renal collecting system. PCNL is therefore recommended as the treatment of choice for renal stones measuring $>15 \mathrm{~mm}$ in diameter ${ }^{12}$. PCNL has proved to be a less morbid procedure compared to open stone surgery.

In the PCNL our target were to improvement of appropriate calyceal puncture, reduce operative time, remove the maximum bulk of the stone burden with the minimum number of punctures and reduce complications. After PCNL our stone-free rates $82 \%$ after $1^{\text {st }}$ procedure. 22 needs auxiliary and ultimate stone free result in $93 \%$. Desai et al., Mishra et al., Winfield et al., de la Rosette et al. and Salaby et al. showed that stone-free rate was $82,5 \%, 72.7,86 \%, 75.7 \%$ \& $74.8 \%$, respectively ${ }^{13-17}$.

In this study operative time ranged between 60-180 minutes, with a mean of $90.83 \pm 29.13$ minutes. Desai et al. showed that median operative time was 65 minutes in case of non staghorn stone and 100 mins in case of staghorn stone ${ }^{\mathbf{1 6}}$. Gupta et al., found that operative time was 45-180 minutes (average 80.2 minutes) ${ }^{\mathbf{1 8}}$. Kurtulus et al. who reported mean operative time was 2.3 hours $^{\mathbf{1 9}}$. Muslumanoglu and associates, 2006 observed the mean operation time was $87.8 \pm 32.5$ (range 180-50) $\mathrm{min}$ in their prospective study ${ }^{20}$. Netto et al. in 2005 conducted a study where the average operative time was 139.1 minutes for single tract PCNL and 134.9 minutes for the multiple access groups. No significant difference was found among the groups ${ }^{21}$. Aron and associates presented data where they found that the mean operative time was 146 minutes $^{22}$. Liatsikos and collaborators in 2005 found that the average operative time of their study was 110 minutes (180$90)^{23}$.

In present study mean blood loss was less. Transfusion was needed in $8(5.63 \%)$ patients. The result was consistent with the previously published 
studies like Singla et al. reported in their study that $18.8 \%$ (28 out of 149) patients were needed blood transfusion in multiple tract group and they found $11.2 \%$ in single tract group of other series ${ }^{\mathbf{2 4}}$. Muslumanogolu and associates, 2006 reported in their study that $18.5 \%$ (5 out of 65 ) patients were needed blood transfusion in multiple tract group and they found $7.6 \%$ (39 out of 210) in single tract group $^{\mathbf{2 0}}$. Netto et al. 2005 compared the blood transfusion between the two groups and were $39.4 \%$ in multi tract group and $14.3 \%$ in single tract group $^{21}$. Liatsikos and collaborators, 2005 observed in their study that the blood transfusion required in $45 \%$ cases of multiple angular renal accesses ${ }^{23}$. Gupta et al. showed that the blood transfusion needed in $4.4 \%$ (4 out of 90$)^{\mathbf{1 8}}$. Desai et al. reported that blood transfusion required in $4.5 \%$ in case of non staghorn stone and $9 \%$ in case of staghorn stone ${ }^{\mathbf{1 6}}$.

In this study perforation of calyceal system occured in $6(4.23 \%)$ patients. Salaby et al. showed that perforation of calyceal system occured in $2(7.69 \%)$ patients ${ }^{15}$. Desai et al. reported that Perforation of collecting system in $2.8 \%$ in case of non staghorn stone and $4.4 \%$ in case of staghorn stone ${ }^{\mathbf{1 6}}$.

In our series eleven patients of PCNL had fever. Fever was associated with urinary tract infection and with rigor following infusion, which resolved quickly after change of antibiotic according to the culture and sensitivity report and/or withdrawal of intravenous fluid. Guohua et al. 2007, in a retrospective study found $7(7 \%)$ patients with a postoperative fever of $38.5^{\circ} \mathrm{C}$ or greater. The 4 patients had bacteremia, which was cured by intravenous antibiotics ${ }^{25}$. Gupta et al. and Mishra et al. showed that post operative fever occurred in $15.6 \%, 18.18 \%$ patients, respectively ${ }^{17,18}$. Desai et al. reported that post operative fever occurred in $8.7 \%$ in case of non staghorn stone and $14.8 \%$ in case of staghorn stone ${ }^{16}$. In a study done by Muslumanoglu and associates 2006 where post operative fever $\left(>38^{\circ} \mathrm{C}\right)$ was occurred about $7.6 \%$ (21 out of 275) patients in multiple tract $\mathrm{PCNL}^{\mathbf{2 0}}$. Aron and associates, 2005 presented data in favors of multi tract PCNL for large complete staghorn calculi found twenty two patients $(21 \%)$ had fever that was treated with broad spectrum antibiotics ${ }^{22}$.

Colonic injury occurs in $2(1.41 \%)$ cases which were managed conservatively. Skolarikos and de la Rosette showed that colonic injury occurred in .02$0.8 \%$ patients $^{\mathbf{2 6}}$. In another international study Mandal et al. showed that colonic injury occurred in $5(0.7 \%)$ patients $^{27}$.

In this study, it has been observed that the mean length of hospital stay 3.28 \pm 0.77 (range 3-7 days). Hegarty and Desai 2006 reported that mean length of hospital stay (days) was 4.67 \pm 0.21 and $3.42 \pm 0.22$ in multiple tract group and single tract group, respectively ${ }^{6}$. In a retrospectively study by Rodrigues Netto and associates in 2005 found that the hospitalization time was not different among the groups, with a mean stay of 3 days ${ }^{21}$. Liatsikos and collaborators observed that the mean length of hospital stay was 4.6 (14-3) days in their series ${ }^{23}$. Singla and associates in 2008 found the hospital stay of their patients was 6.8 (28-3) days ${ }^{24}$. Muslumanoglu et al. reported in their study the mean hospital stay was 2.4 \pm 1.1 (range 1-7 days) ${ }^{\mathbf{2 0}}$. Gupta et al. and Mishra et al. showed that hospital stay 2.4 (1-7 days) days and 72.75 hours, respectively ${ }^{17,18}$. Desai et al. reported that median hospital stay 3 days in $8.7 \%$ in case of non staghorn stone and 4 days in case of staghorn stone ${ }^{\mathbf{1 6}}$.

Conclusion: PCNL is a versatile technique for both simple \& complex renal stone in all age groups with minimal patient's morbidity \& high satisfaction.

\section{References}

1. Skolarikos A, Alivizatos G, de la Rosette JJ. Percutaneous nephrolithotomy and its legacy. European urology. 2005; 47(1):22-8.

2. Hosseini MM, Basiri A, Moghaddam SM. Percutaneous nephrolithotomy of patients with staghorn stone and incidental purulent fluid suggestive of infection. Journal of endourology/Endourological Society. 2007; 21(12):1429-32.

3. Honeck P, Wendt-Nordahl G, Krombach P, Bach T, Hacker A, Alken P, et al. Does open stone surgery still play a role in the treatment of urolithiasis? Data of a primary urolithiasis center. Journal of endourology/ Endourological Society. 2009; 23(7):1209-12.

4. Cormio L, Perrone A, Di Fino G, Ruocco N, De Siati M, de la Rosette J, et al. TachoSil((R)) sealed tubeless percutaneous nephrolithotomy to reduce urine leakage and bleeding: outcome of a randomized controlled study. The Journal of urology. 2012; 188(1):145-50.

5. Keoghane SR, Cetti RJ, Rogers AE, Walmsley BH. Blood transfusion, embolisation and nephrectomy after percutaneous nephrolithotomy (PCNL). BJU international. 2013; 111(4):628-32.

6. Hegarty NJ, Desai MM. Percutaneous nephrolithotomy requiring multiple tracts: comparison of morbidity with single-tract procedures. Journal of endourology / Endourological Society. 2006; 20(10):753-60.

7. Gupta R, Kumar A, Kapoor R, Srivastava A, Mandhani A. Prospective evaluation of safety and efficacy of the supracostal approach for percutaneous nephrolithotomy. BJU international. 2002; 90(9):809-13.

8. Hafron J, Fogarty JD, Boczko J, Hoenig DM. Combined ureterorenoscopy and shockwave lithotripsy for large renal stone burden: an alternative to percutaneous nephrolithotomy? Journal of endourology/Endourological Society. 2005; 19(4): 464-8. 
9. Marguet CG, Springhart WP, Tan YH, Patel A, Undre $\mathrm{S}$, Albala DM, et al. Simultaneous combined use of flexible ureteroscopy and percutaneous nephrolithotomy to reduce the number of access tracts in the management of complex renal calculi. BJU international. 2005; 96(7):1097-100.

10. Rudnick DM, Stoller ML. Complications of percutaneous nephrostolithotomy. The Canadian journal of urology. 1999; 6(5):872-5.

11. Dasgupta P, Jones A, Gill IS. Robotic urological surgery: a perspective. BJU international. 2005; 95(1): 20-3.

12. Michel MS, Trojan L, Rassweiler JJ. Complications in percutaneous nephrolithotomy. European urology. 2007; 51(4):899-906; discussion.

13. Winfield HN, Weyman P, Clayman RV. Percutaneous nephrostolithotomy: complications of premature nephrostomy tube removal. The Journal of urology. 1986; 136(1):77-9.

14. de la Rosette J, Assimos D, Desai M, Gutierrez J, Lingeman J, Scarpa R, et al. The Clinical Research Office of the Endourological Society Percutaneous Nephrolithotomy Global Study: indications, complications, and outcomes in 5803 patients. Journal of endourology/Endourological Society. 2011; 25(1): 11-7.

15. Shalaby MM, Abdalla MA, Aboul-Ella HA, ElHaggagy AM, Abd-Elsayed AA. Single puncture percutaneous nephrolithomy for management of complex renal stones. BMC research notes. 2009; 2:62.

16. Desai M, De Lisa A, Turna B, Rioja J, Walfridsson H, D'Addessi A, et al. The clinical research office of the endourological society percutaneous nephrolithotomy global study: staghorn versus nonstaghorn stones. Journal of endourology/Endourological Society. 2011; 25(8):1263-8.

17. Mishra S, Sabnis RB, Kurien A, Ganpule A, Muthu V, Desai M. Questioning the wisdom of tubeless percutaneous nephrolithotomy (PCNL): a prospective randomized controlled study of early tube removal vs tubeless PCNL. BJU international. 2010; 106(7):10458; discussion 8-9.

18. Gupta NP, Mishra S, Nayyar R, Seth A, Anand A. Comparative analysis of percutaneous nephrolithotomy in patients with and without a history of open stone surgery: single center experience. Journal of endourology/Endourological Society. 2009; 23(6): 913-6.
19. Kurtulus FO, Fazlioglu A, Tandogdu Z, Aydin M, Karaca S, Cek M. Percutaneous nephrolithotomy: primary patients versus patients with history of open renal surgery. Journal of endourology / Endourological Society. 2008; 22(12):2671-5.

20. Muslumanoglu AY, Tefekli A, Karadag MA, Tok A, Sari E, Berberoglu Y. Impact of percutaneous access point number and location on complication and success rates in percutaneous nephrolithotomy. Urologia internationalis. 2006; 77(4):340-6.

21. Netto NR, Jr., Ikonomidis J, Ikari O, Claro JA. Comparative study of percutaneous access for staghorn calculi. Urology. 2005; 65(4):659-62; discussion 62-3.

22. Aron M, Yadav R, Goel R, Kolla SB, Gautam G, Hemal AK, et al. Multi-tract percutaneous nephrolithotomy for large complete staghorn calculi. Urologia internationalis. 2005; 75(4):327-32.

23. Liatsikos EN, Kapoor R, Lee B, Jabbour M, Barbalias $\mathrm{G}$, Smith AD. "Angular percutaneous renal access". Multiple tracts through a single incision for staghorn calculous treatment in a single session. European urology. 2005; 48(5):832-7.

24. Singla M, Srivastava A, Kapoor R, Gupta N, Ansari MS, Dubey D, et al. Aggressive approach to staghorn calculi-safety and efficacy of multiple tracts percutaneous nephrolithotomy. Urology. 2008;71(6): $1039-42$.

25. Guohua Z, Zhong W, Li X, Wu K, Chen W, Lei M, et al. Minimally invasive percutaneous nephrolithotomy for staghorn calculi: a novel single session approach via multiple $14-18 \mathrm{Fr}$ tracts. Surgical laparoscopy, endoscopy \& percutaneous techniques. 2007; 17(2): 124-8.

26. Skolarikos A, de la Rosette J. Prevention and treatment of complications following percutaneous nephrolithotomy. Current opinion in urology. 2008; 18(2): 229-34.

27. Mandal S, Goel A, Kathpalia R, Sankhwar S, Singh V, Sinha RJ, et al. Prospective evaluation of complications using the modified Clavien grading system, and of success rates of percutaneous nephrolithotomy using Guy's Stone Score: A singlecenter experience. Indian journal of urology: IJU: journal of the Urological Society of India. 2012; 28(4): 392-8. 